\title{
Conservación del forraje de la Typha domingensis (Typhaceae): ensilaje y henificación
}

\author{
Rodolfo WingChing-Jones ${ }^{1} \&$ José Carlos Leal Rivera ${ }^{2}$ \\ 1. Escuela de Zootecnia, Centro de Investigación en Nutrición Animal, Universidad de Costa Rica, San José, Costa Rica; \\ rodolfo.wingching@ucr.ac.cr \\ 2. Humedal Palustrino Corral de Piedra, Área de Conservación Tempisque, Sistema Nacional de Áreas de Conservación (SINAC), San José, \\ Costa Rica; lealriveraj@hotmail.es
}

Recibido 18-VII-2017 • Corregido 05-IX-2017 • Aceptado 19-IX-2017

\begin{abstract}
Conservation of cattail, Typha domingensis (Typhaceae) forage: Silage and hay. Integrating the management of the southern cattail into cattle feeding practices provides, from a management perspective, keeping water mirrors for birds, and, for producers, a food source for ruminant animals when low rains reduce forage growth. We determined the suitability of the plant as hay or silage after four months of re-growth. For hay, we dried the forage in sunlight from $10 \mathrm{AM}$ to $2 \mathrm{PM}$ for 4 days. In the case of silage, we added $3 \% \mathrm{w} / \mathrm{w}$ molasses, and tried three levels of urea $(0.5,1$ and $1.5 \% \mathrm{w} / \mathrm{w})$ at a constant level of molasses $(3 \% \mathrm{w} / \mathrm{w})$. This hay has a better crude protein and IVDMD profile than previously reported values for Transvala hay, cattail hay is an acceptable alternative source of forage near the wetland. Silage has a suitable behavior when exposed to an anaerobic fermentation, which together with the addition of urea and molasses, preserves and increases nitrogen.
\end{abstract}

Key words: Dehydration, anaerobic fermentation, crude protein, digestibility, wetland
RESUMEN: Integrar la gestión de la tifa en prácticas de alimentación de ganado proporciona, desde una perspectiva de gestión, mantenimiento de espejos de agua para aves $y$, para productores, la fuente de alimento para animales rumiantes cuando las lluvias bajas reducen el crecimiento de forraje. Determinamos la capacidad de la tifa cosechada a cuatro meses de rebrote de ser henificada y ensilada. Para el heno, hemos secado el forraje bajo la luz del sol de 10am a $2 \mathrm{pm}$ durante 4 días. En el caso del ensilado, se añadió melaza melazas al $3 \% \mathrm{p} / \mathrm{p}$, y se probaron tres niveles de urea $(0,5,1$ y $1,5 \% \mathrm{p} / \mathrm{p})$ a un nivel constante de melaza (3\% p/p). Este heno de tifa contiene mejor valor de proteína cruda y perfil DIVMS que el informado anteriormente para Transvala, la tifa es una fuente alternativa aceptable de forraje cerca del humedal. El ensilado tiene un comportamiento adecuado cuando se expone a la fermentación anaeróbica, que, junto con la adición de urea y melaza, conserva y aumenta el nitrógeno.

Palabras clave: Deshidratación, fermentación anaeróbica, proteína cruda, digestibilidad, humedal
Según estudio realizado por la Escuela de Zootecnia de la Universidad de Costa Rica, el forraje de tifa, cosechada a 4 meses de rebrote, presenta un perfil nutricional igual o superior a los materiales henificados en el área de influencia del humedal Corral de Piedra, Nicoya (WingChing-Jones \& Leal Rivera, 2014). Está zona se caracteriza por su vocación ganadera; en el censo agropecuario del 2014 (INEC, 2014), se determinaron 1949 fincas en el cantón de Nicoya, con una extensión total en hectáreas de 69690,2ha, de las cuales el 50,77\% están cubiertas por plantas forrajeras destinadas a la alimentación de animales rumiantes (35385,8 ha). Además, presenta una población total de vacunos de 38102 animales, equivalente al 2,98\% de la población nacional (1 278817 animales) (INEC, 2014).
Por otro lado, el cantón de Nicoya es el cantón número 2 de la provincia de Guanacaste (LA GACETA, 2009) la cual se caracteriza por presentar una estación lluviosa y otra seca bien definida (IMN-CRRH, 2008), lo cual, provoca una estacionalidad en la productividad de los forrajes y en la disponibilidad de alimento para los semovientes (Campos, 2011). Dentro de las estrategias empleadas por los productores de la zona para afrontar la reducción en la disponibilidad de forraje durante estos periodos, se encuentra la suplementación de los animales con forrajes conservados (henificación y ensilaje); bancos forrajeros, el uso de subproductos agroindustriales; la reducción de la carga animal por traslado o venta de animales y la combinación de dos o más alternativas (Campos, 2011). Debido a estas condiciones, se nota una reducción en la 
condición corporal de los animales, en las fincas que no guardan alimentos, ni brindan suplementación.

Integrar el manejo de la tifa en prácticas de alimentación de vacunos en el área de influencia del Humedal Corral de Piedra, Nicoya, permite desde una perspectiva de manejo del área de conservación, mantener el espejo de agua libre para la visita de aves (Plasencia \& Kvet, 1993), y en el contexto de vinculación con los productores del área de influencia del humedal, el desarrollo de estrategias de uso de la tifa como fuente de alimento para animales rumiantes durante los periodos de reducción del crecimiento del forraje, debidas al comportamiento de las lluvias. Por tal motivo, valorar la capacidad de conservación de este material fue el objetivo de este trabajo, donde se procedió a ensilar la tifa con o sin adición de melaza y urea, como también, analizar el comportamiento de este material a procesos de deshidratación.

\section{METODOLOGÍA}

Ubicación del sistema: Esta prueba se realizó en el Humedal Palustrino Corral de Piedra, el cual se ubica en Corral de Piedra, en Corralillo de Nicoya, Guanacaste, durante el año 2015 en el mes de enero. Para tal fin, se escogió un lote de $1000 \mathrm{~m}^{2}$, el cual se uniformizó mediante corta con machete, para ser cosechado a cuatro meses de rebrote, para obtener el material que se va a conservar por medio del ensilado y la henificación.

Elaboración del ensilaje: Se picó el material de tifa con machete, a un tamaño de partícula igual o menor a $3 \mathrm{~cm}$ de largo. Después de picado el material se mezcló por cinco minutos con ayuda de una pala y se separó en cinco partes iguales. Cada parte fue considerada un tratamiento a ensilar; una quinta parte se ensilo sin la aplicación de melaza y sin urea (UM) (Tratamiento control), una segunda parte, se le adicionó $3 \%$ de melaza $(p / p)$ (U3M) y las últimas tres partes, se les aplicó por separado tres niveles crecientes de urea $(0,5,1$ y $1,5 \% \mathrm{p} / \mathrm{p})$ con un nivel constante de $3 \%(\mathrm{p} / \mathrm{p})$ de melaza $(0,5 \mathrm{U} 3 \mathrm{M}, 1 \mathrm{U} 3 \mathrm{M}$ y 1,5U3M respectivamente). Después de la aplicación de los aditivos, cada parte por separado, se mezcló hasta obtener homogeneidad y se empacó en bolsas transparentes con capacidad de un kilogramo. A cada bolsa se le extrajo el aire con una bomba de succión, se amarró con una cinta adhesiva y se mantuvo a condiciones ambientales de temperatura y humedad durante 30 días. Pasado el periodo de fermentación, las bolsas fueron abiertas y se les retiró el material en mal estado. El material que se consideró en buen estado, se empacó en bolsas identificadas y se trasladaron al laboratorio de bromatología del Centro de Investigación en Nutrición Animal (CINA).

El análisis organoléptico de los materiales ensilados se realizó en el momento que las bolsas con el material ensilado se abrieron, para tal fin, se siguió el procedimiento descrito por Betancourt et al. (2005), el cual clasifica los materiales según color, textura y olor obtenido en cada tratamiento.

Elaboración del heno: El material cosechado a 4 meses se picó a un tamaño de partícula de $3 \mathrm{~cm}$ con ayuda de un machete, hasta alcanzar una cantidad de $10 \mathrm{Kg}$ de material picado. Este material se colocó sobre un área de 15 metros cuadrados ( $2 \mathrm{~m} \times 7,5 \mathrm{~m}$ ) de plástico negro, de manera que se alcanzará una capa homogénea de $3 \mathrm{~cm}$ de grosor. Durante cuatro días seguidos, este material se expuso a las condiciones ambientales presentes en la localidad Corral de Piedra, Nicoya, entre las diez y catorce horas del día, para un total de 16h de exposición. Terminado este periodo, se recolectaron cinco muestras compuestas de un kilogramo de peso cada una y se trasladaron al laboratorio de bromatología del Centro de Investigación en Nutrición Animal (CINA).

Análisis de laboratorio: Mediante la metodología de la AOAC (2000) se determinó el porcentaje de materia seca (MS) en estufa a $60^{\circ} \mathrm{C}$ durante $48 \mathrm{~h}$, el contenido de proteína cruda (PC) por el método de Kjedalh y la digestibilidad in vitro de la materia seca (DIVMS) a los materiales ensilados y henificados, siguiendo la metodología de Van Soest y Robertson (1985). En el caso de los materiales ensilados, el pH se determinó utilizando un medidor de $\mathrm{pH}$ con electrodo de hidrógeno y el nitrógeno amoniacal fue analizado utilizando la metodología descrita por Tobía (2004).

Estimación de la energía del ensilaje: Por medio de la ecuación que relaciona la digestibilidad de la tifa con su contenido de nutrimentos digestibles totales (NDT) en plantas con 4 y 12 meses de rebrote descrita por WingChing-Jones y Leal-Rivera (2014), se procedió a estimar el valor de NDT de las mezclas ensiladas y del material henificado, según la siguiente ecuación: $Y=-0,2239 X^{2}+28 X-0,5542\left(R^{2}=0,5542\right)$, donde $Y=$ nutrientes digestibles totales y $X=$ porcentaje de digestibilidad in vitro de la materia seca. Posterior al cálculo de los nutrientes digestibles totales (NRC, 2001), se procedió a estimar los contenidos de energía digestible (ED), metabolizable (EM), neta de lactancia (ENI), neta de 
mantenimiento (ENm) y neta de ganancia $(\mathrm{ENg})$ de los materiales (Weis, 2004).

Análisis de la información: En el caso de los resultados de material fresco de tifa y el heno, se utilizaron medidas de tendencia central para el desarrollo de los gráficos que permiten comparar su contenido de materia seca, proteína cruda y digestibilidad. En relación a los materiales ensilados, con ayuda del programa SAS, se realizó un análisis de varianza (ANDEVA) para definir el efecto de los niveles crecientes de urea y melaza sobre los contenidos de materia seca, proteína cruda, digestibilidad, pH y nitrógeno amoniacal de las mezclas ensiladas (SAS, 2003). Al momento de determinar diferencias entre medias, se procedió a aplicar la prueba de Duncan, la cual permite obtener diferencias con una probabilidad de $p<0,05$ en los efectos significativos.

\section{RESULTADOS}

Valor de materia seca, proteína cruda y digestibilidad in vitro de la materia seca de la tifa cosechada a cuatro meses de rebrote. Según la información descrita en la figura 1, los contenidos de materia seca, proteína cruda y de digestibilidad in vitro de la materia seca, presentaron valores mínimos y máximos de 17,25 a 19,65\%; 6,50 a $6,92 \%$ y 51,0 a $55,8 \%$ respectivamente.

Heno. El heno de tifa, presenta un contenido de materia seca menor, pero 1,99 veces más proteína cruda y 1,22 veces más digestibilidad que el heno de transvala (Fig. 2). Lo cual permite considerar este material como sustituto del heno de transvala en el cuido de animales rumiantes en estas zonas. El proceso de deshidratación empleado, permitió incrementar el contenido de materia seca del material en 57,35 unidades porcentuales. Incremento que permite almacenar este material a corto plazo en lugares secos, sin el inconveniente que se genere un deterioro del mismo.

Ensilaje. Los ensilajes fueron valorados de forma organoléptica y química. De las características organolépticas, el olor que presentaron los materiales fue dulce vinagroso, la coloración fue verde amarillento y presentaron una facilidad de separación del material picado.

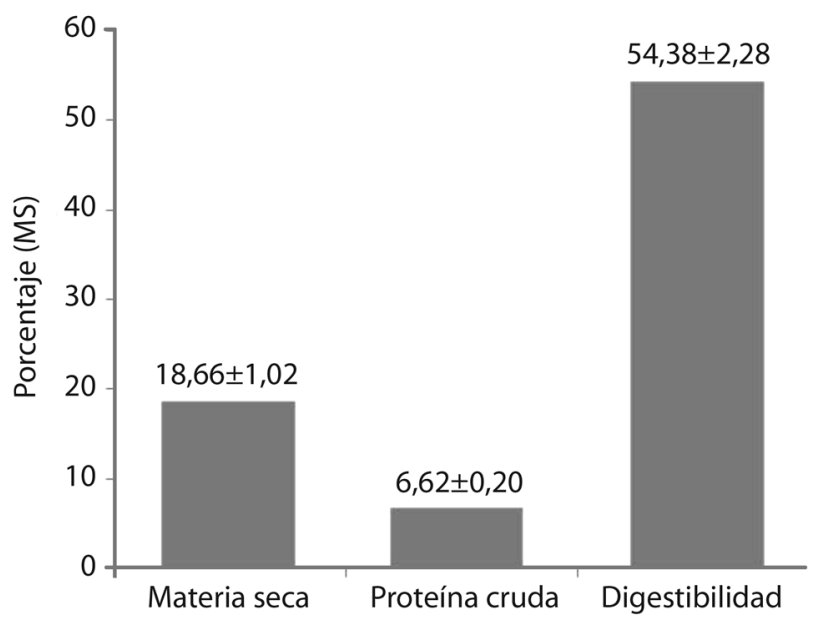

Fig. 1. Contenidos de materia seca, proteína cruda y digestibilidad in vitro de la materia seca de la tifa cosechada a cuatro meses de rebrote.

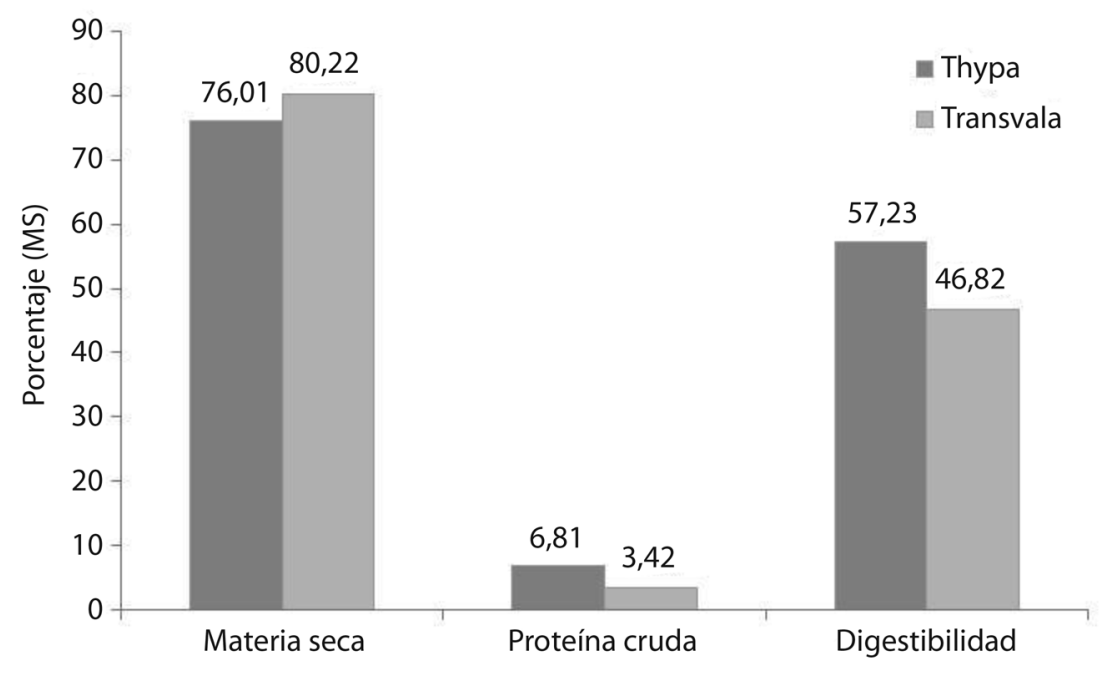

Fig. 2. Comparación del contenido de materia seca, proteína cruda y digestibilidad del heno de tifa cosechado a cuatro meses de rebrote con el heno de transvala. 
Lo cual es indicativo de un material que se conservó de forma adecuada.

Materia seca: La aplicación de un aditivo (melaza + urea) para el proceso fermentativo, permite incrementar en 1,18 unidades porcentuales el contenido de materia seca del ensilaje de tifa, mientras que la melaza sola incrementó en 0,87 unidades porcentuales, ambos casos con respecto al tratamiento control $(p<0,05)$. En el caso de valorar el efecto aditivo de la urea con la melaza, se observa un incremento de 0,31 unidades porcentuales en la materia seca del ensilado debida al aporte de la urea, lo cual se asocia a una utilización de esta forma de nitrógeno no proteico por parte de los microorganismos presentes en el ensilaje. Por los valores obtenidos de materia seca, se considera un ensilaje alto en humedad, lo cual podría generar un efecto de dilución de los componentes nutricionales, a la hora de la suplementación.

Proteína cruda: Se nota en la figura 3 , un incremento en el contenido de PC de los materiales, según el nivel de urea adicionado $(p<0,05)$. El incremento promedio en PC

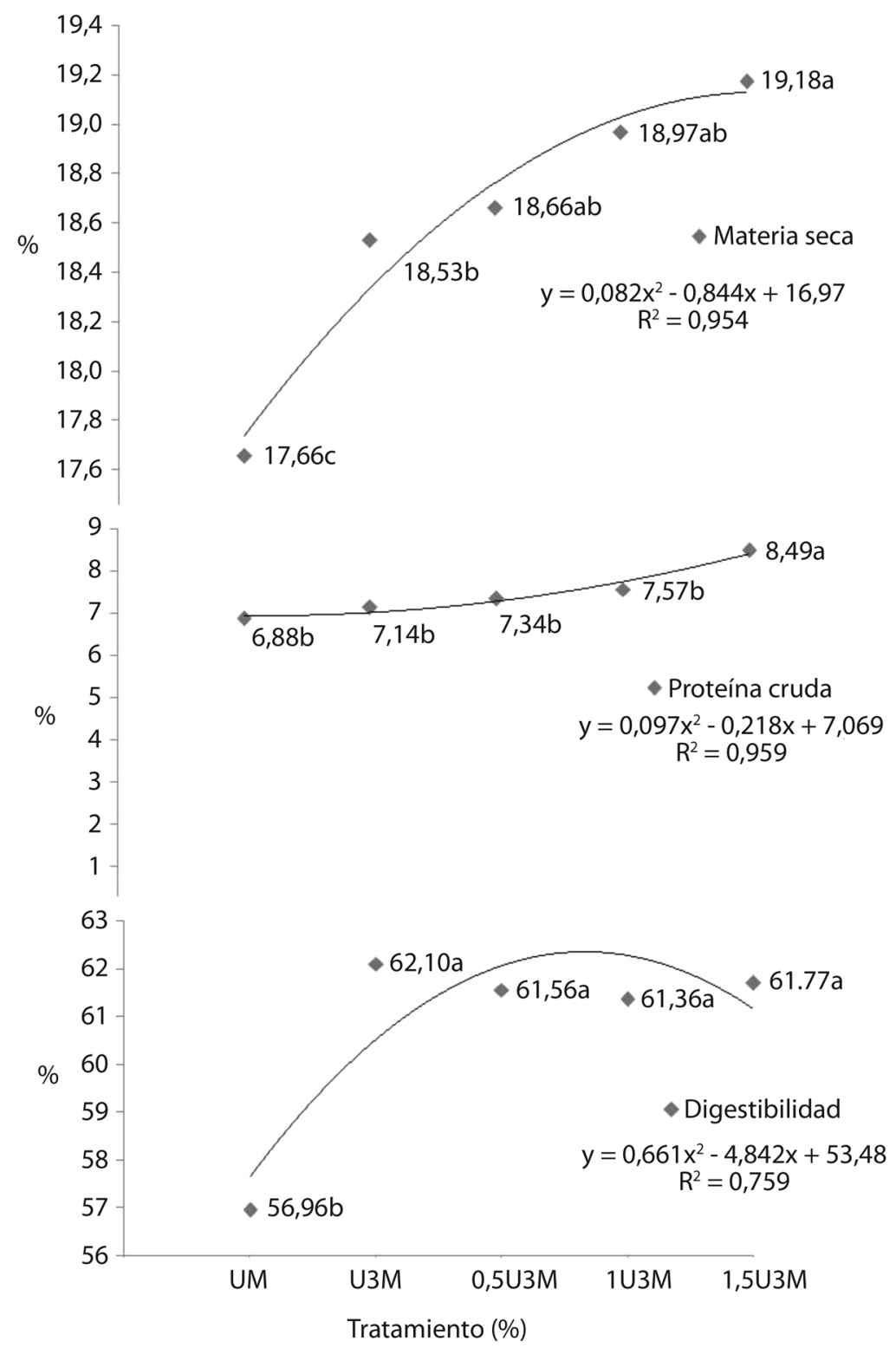

Fig. 3. Contenido de materia seca, proteína cruda y digestibilidad del ensilaje de tifa cosechada a cuatro meses de rebrote con niveles crecientes de urea y tres por ciento de melaza. $U M=\sin$ urea ni melaza; $U 3 \mathrm{M}=\sin$ urea pero $3 \%$ melaza; $0,5 \mathrm{U} 3 \mathrm{M}=0,5 \%$ urea y $3 \%$ melaza; $1 \mathrm{U} 3 \mathrm{M}=1 \%$ de urea y $3 \%$ de melaza y $1,5 \mathrm{U} 3 \mathrm{M}=1,5 \%$ urea y $3 \%$ melaza. 
por la adición de los aditivos utilizados en este trabajo es de 0,75 unidades porcentuales de PC en comparación con el tratamiento control, si este aditivo es solo melaza el incremento en unidades porcentuales es de 0,26 de PC. En el caso del efecto aditivo por la adición de urea a un ensilaje con una base de $3 \%$ de melaza fue de 0,66 unidades porcentuales de PC. En promedio, el valor de PC de los ensilados, presentan el valor mínimo de N, que requiere el rumen para funcionar, lo que adicionar urea al ensilado, permite mejorar este ensilaje. Lo cual genera una alternativa alimenticia, para los productores que se encuentran en el área de influencia del proyecto.

Digestibilidad in vitro de la Materia Seca: La digestibilidad de los materiales se mejora en 4,72 unidades porcentuales al adicionar la melaza y la urea en comparación con el material sin aditivos (Fig. 3$)(p<0,05)$. Se encontró un efecto positivo en el aprovechamiento del ensilado al aplicar la melaza, sin embargo, al adicionar la melaza con la urea, se da una merma en el aprovechamiento, que se mejora según el incremento de la urea adicionada.

Nitrógeno amoniacal y $\mathbf{p H}$ de los ensilados: Se nota en la figura 4, una tendencia a incrementar en el contenido de nitrógeno amoniacal, debida a la adición de urea $(p>0,05)$. En el caso del $p H$ de los ensilados, la adición de melaza $(p<0,05)$, permite disminuir el $\mathrm{pH}$ del material por debajo de 4 , efecto que se reduce conforme se adicionan los niveles crecientes de urea.

Contenidos de energía: Los valores estimados de nutrimentos digestibles totales (NDT), energía digestible $(E D)$, energía metabolizable (EM), energía neta de mantenimiento (ENM), de ganancia $(E N g)$ y de lactancia $\left(E_{L}\right)$ de los ensilajes, superan en promedio a los valores obtenidos en heno en 5,35 unidades porcentuales, y en 0,24; 0,$19 ; 0,18 ; 0,17$ y 0,13 kilocalorías por kilogramo en las fracciones energéticas de ED, EM, ENM, $\mathrm{EN}_{g}$ y EN $\mathrm{EN}_{\mathrm{L}}$ respectivamente. También se observa en el cuadro 1, que los materiales ensilados sin adición de ningún aditivo, presentan valores de energía similares a los del heno, por lo cual el decidir qué estrategia de conservación utilizar dependerá de la palatabilidad del material, ligado al costo de producción del kilogramo de materia seca. Además, el uso de aditivos en las mezclas ensiladas, incrementa en 7 unidades porcentuales el contenido de NDT de los materiales, lo que se traduce en mayor aporte energético en las fracciones determinadas.

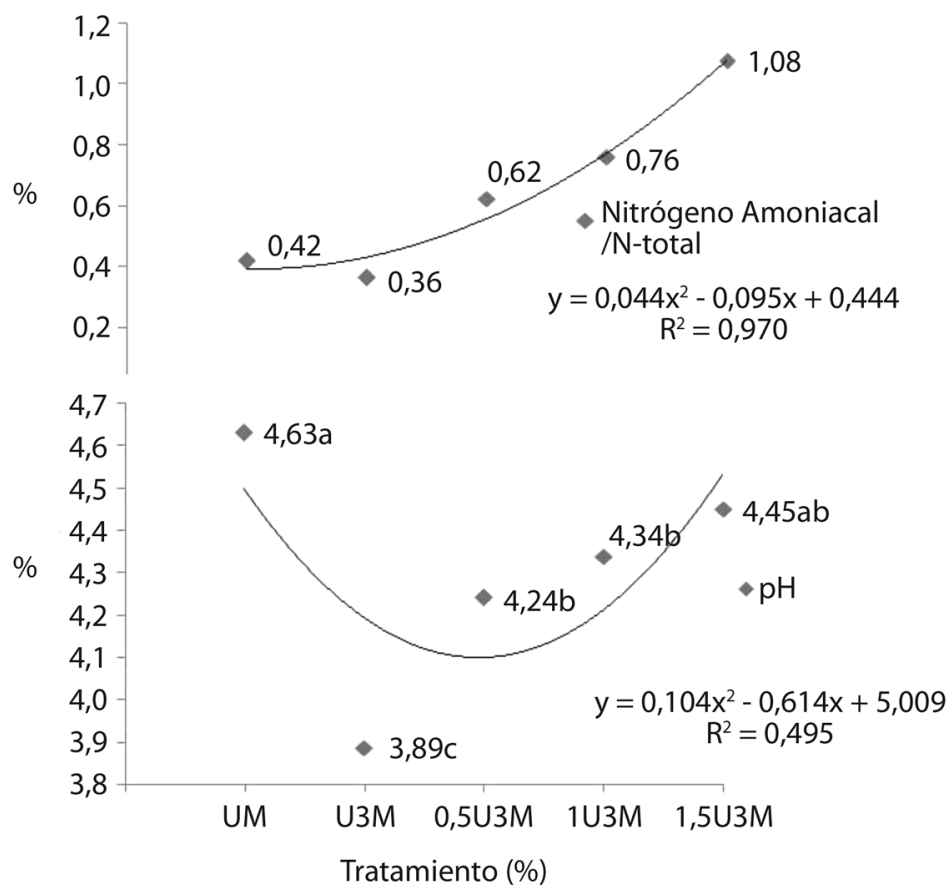

Fig. 4. Valor de pH y nitrógeno amoniacal del ensilaje de tifa cosechada a cuatro meses de rebrote con niveles crecientes de urea y tres por ciento de melaza. $\mathrm{UM}=\sin$ urea ni melaza; $\mathrm{U} 3 \mathrm{M}=\sin$ urea pero $3 \%$ melaza; $0,5 \mathrm{U} 3 \mathrm{M}=0,5 \%$ urea y $3 \% \mathrm{melaza} ; 1 \mathrm{U} 3 \mathrm{M}=1 \%$ de urea y $3 \%$ de melaza y $1,5 \mathrm{U} 3 \mathrm{M}=1,5 \%$ urea y $3 \%$ melaza. 
CUADRO

Contenidos estimados de energía del heno y ensilajes de tifa con adición de urea y melaza

\begin{tabular}{ccccccccc} 
& Urea $(\% \mathrm{p} / \mathrm{p})$ & Melaza $(\% \mathrm{p} / \mathrm{p})$ & $\mathrm{NDT} \%$ & $\mathrm{ED}$ & $\mathrm{EM}$ & $\begin{array}{c}\text { ENM } \\
\text { Mcal } / \mathrm{kg}\end{array}$ & ENG & ENL \\
Ensilaje & 0 & 0 & 53,57 & 2,36 & 1,94 & 1,09 & 0,54 & 1,19 \\
& 0 & 3 & 61,02 & 2,69 & 2,21 & 1,34 & 0,77 & 1,38 \\
& 0,5 & 3 & 60,79 & 2,68 & 2,20 & 1,34 & 0,76 & 1,37 \\
& 1 & 3 & 60,67 & 2,68 & 2,19 & 1,33 & 0,76 & 1,37 \\
& 1,5 & 3 & 60,86 & 2,68 & 2,20 & 1,34 & 0,76 & 1,37 \\
Heno & & & 54,03 & 2,38 & 1,95 & 1,11 & 0,55 & 1,20 \\
\hline
\end{tabular}

\section{DISCUSIÓN}

La tifa cosechada a 4 meses de rebrote presentó mayor contenido de materia seca $(14,56 \%)$, menor contenido de proteína $(7,83 \%)$ y menor digestibilidad in vitro $(59,96 \%)$ respecto a lo obtenido por WingChing-Jones y Leal Rivera (2014) en la caracterización nutricional de la tifa, cosechada a 4 y 12 meses de rebrote. Esta diferencia se podría asociar en el caso de la materia seca a un periodo de tiempo mayor entre cosecha y picado; lo cual permitió pérdida de humedad de forma natural y a las condiciones ambientales presentes durante la ejecución de esta propuesta de investigación. Al valorar las diferencias en los contenidos de proteína y la digestibilidad del material, se debe considerar la altura de cosecha y la presencia de partes de la base de la planta (material fibroso), componentes de la pared celular que diluyen el contenido de proteína y disminuyen la degradabilidad del material por los microorganismos ruminales.

En el caso del heno de tifa, el secado de este material de forma artesanal, permitió alcanzar valores similares de materia seca al heno de transvala analizado por WingChing-Jones y Alvarado (2009). En el caso de las otras dos fracciones analizadas, el manejo de picar el material a mano y de exponerlo al sol durante periodos intermedios de 4 horas, podrían ser factores a considerar para justificar las diferencias en los contenidos de proteína cruda y digestibilidad entre los dos henos, debido a que el heno de transvala, queda expuesto durante varios días a condiciones de secado y humedecimiento (periodos nocturnos) hasta que se coseche, lo cual genera procesos de recalentamiento del material, lo que conlleva al gasto de los carbohidratos y proteínas solubles del forraje, por los microorganismos que lo utilizan como sustrato (Collins, 1995). Además, es importante considerar la ausencia de prácticas agronómicas en el cultivo del forraje destinado para la producción de pacas de heno y la edad de cosecha del material, donde se busca mayor producción por hectárea en perjuicio de la calidad del material (Morales, Acuña \& Cruz, 2003).

El bajo contenido de materia seca del material fresco, podría generar pérdidas de nutrimentos durante el proceso de ensilaje de tifa, debida a la producción de efluentes y a procesos fermentativos parciales (MC Donald, 1981). Por tal motivo, el uso de aditivos como la melaza favorece la conservación de la materia seca del material, debido a que aumenta el contenido de materia seca $(68,8$ a $87 \%)$ (Mata, 2011) y el contenido de carbohidratos solubles para la fermentación (Tobia, 2004). En el caso de la adición de la urea, se justifica por el bajo contenido de proteína que presenta la planta de tifa, cantidad que podría comprometer su consumo por el animal y de su aprovechamiento a nivel ruminal, debido a que no alcanza el mínimo requerido de proteína en forrajes (7\% PC) para mantener un buen consumo (Rojas, Gómez \& Aguirre, 1995) y la actividad de los microorganismos del rumen.

El comportamiento de la digestibilidad del ensilaje de tifa sin aditivos es similar a la descrita por WingChingJones y Leal Rivera (2014) para el forraje de tifa cosechada a 4 meses, comportamiento que indica, que la conservación de este material, no afectaría su aprovechamiento a nivel ruminal. Al adicionarle los carbohidratos solubles vía melaza y el nitrógeno no proteico (Urea), se nota una mejora en el aprovechamiento del ensilado de tifa, similar a los datos descritos por Martínez-Machado (2015) para la digestibilidad de la materia seca de los forrajes de Estrella africana (66,5\%), Ratana (68,5\%), Guinea (54,5\%), Mulato $(65,8)$, King grass $(62,2 \%)$ y Camerún $(57,3 \%)$, comportamiento que potencia su uso en la alimentación de rumiantes en el área de influencia del humedal.

La mejora en el aprovechamiento del material, podría asociarse a una mayor actividad de los microorganismos durante el proceso fermentativo, producto a un mejor acoplamiento de sustrato entre las formas solubles de nitrógeno que presenta la tifa de forma natural y el 
nitrógeno no proteico con la melaza, que mejora la accesibilidad de los microorganismos ruminales a la pared celular de la tifa. Esta mejora al incluir los aditivos, se refleja en las fracciones energéticas del ensilado, donde el incremento de 7 unidades porcentuales en los nutrientes digestibles totales (NDT), le permite satisfacer los requerimientos de NDT sin restricción de consumo de materia seca del mantenimiento de una oveja (55\%) y de una oveja seleccionada para remplazo (59\%), para el mantenimiento de un búfalo con un peso vivo de $1000 \mathrm{~kg}$ (56\%), un toro de $800 \mathrm{Kg}$ PV con una ganancia de $0,5 \mathrm{Kg} /$ día (50\%), una cabra en mantenimiento (56\%) y una novilla de $350 \mathrm{Kg}$ PV con una ganancia de 0,6Kg/día (60\%).

Según el comportamiento fermentativo de los ensilados, se podría indicar que se conservó la proteína de la tifa, debido a que los valores de nitrógeno amoniacal $\left(\mathrm{N}-\mathrm{NH}_{3} / \mathrm{N}\right.$-total) no superan el $2 \%$ en el material ensilado, según Tobia y Vargas (2000), un valor por debajo de 7\% $\mathrm{N}-\mathrm{NH}_{3} / \mathrm{N}$-total se considera óptimo para el proceso. En el caso del pH de los materiales, estos superan el valor deseado entre 3,9 y 4,2 descrito por Tobia y Vargas (2000), en los materiales sin aditivo, se podría asociar a que la tifa presenta una baja concentración de carbohidratos soluble, y a los ensilados con adiciones crecientes de urea, por el efecto buffer que presenta este aditivo, por la liberación de amonio durante su descomposición en otras moléculas nitrogenadas (McDonald, 1981).

La caracterización nutricional del heno y del ensilaje de tifa, potencian la conservación de este material como alternativa de alimentación de animales rumiantes, para los periodos críticos de disponibilidad de forraje, en las áreas aledañas al humedal Corral de Piedra. Al valorar estas alternativas alimenticias, es importante considerar el costo de producción del kilogramo de materia seca del heno o ensilaje de tifa producido, debido a que se asocian actividades de corte y acarreo, picado, aditivos (melaza y urea), silos o bolsas y la elaboración del ensilaje; y el cuido del material durante su deshidratación (Villalobos-Villalobos, Arce-Cordero \& WingChing-Jones, 2015). Por otro lado, se debe considerar el número de animales a suplementar, la cantidad a suplementar, el periodo de la suplementación y la posible área que se le podría asignar a cada productor, como zonas para control de esta planta invasora.

\section{REFERENCIAS}

AOAC (Association of Official Agricultural Chemist). (2000). Official methods. 17th Ed. Washington D.C., EEUU: The Association of Official Analytical Chemists.
Betancourt, J.C. (2004). Caracterización nutricional y productiva de material fresco y ensilado de maní forrajero (Arachis pintoi) cultivado en asocio con maíz (Zea mays), a tres densidades de siembra. Tesis inédita de Maestría. Universidad de Costa Rica, Costa Rica.

Campos, P. (2011). Evaluación de la toma de decisiones de productores ganaderos respecto a las medidas de adaptación a cambio climático en Guanacaste, Costa Rica. Tesis inédita de Maestría. Centro Agronómico Tropical de Investigaciones y Enseñanza, Turrialba, Cartago, Costa Rica.

Collins, M. (1995). Hay preservation effects on yield and quality. pp: 67-89; In: Moore, K., Peterson, M. Post-Harvest physiology and preservation of forages. CCSSA Special Publication 22. Madison, Winconsin, EEUU: American Society of Agronomy, Inc. Crop Science society of America, Inc.

IMN-CRRH (2008). Clima, variabilidad y cambio climático en Costa Rica. Segunda Comunicación Nacional de Cambio Climático. Ministerio de Ambiente Energía y Telecomunicaciones (MINAET), Instituto Meteorológico Nacional (IMN), Programa de las Naciones Unidad para el Desarrollo (PNUD), Comité Regional de Recursos Hidráulicos (CRRH). San José, Costa Rica.

INEC (Instituto Nacional de Estadística y Censos). (2014). VI Censo Nacional Agropecuario: Actividades Pecuarias, Prácticas y Servicios Agropecuarios. 1 ed. San José. Costa Rica: INEC.

LA GACETA (2009, 5 de mayo). División territorial administrativa de Costa Rica. Decreto N 35213-MG. LA GACETA N ${ }^{\circ} 85$.

Mata, L. (2011). Tabla de composición de materias primas usadas en alimentos para animales. Centro de Investigación en Nutrición Animal (CINA), Universidad de Costa Rica, San José, Costa Rica: SIEDIN

Mc Donald, P. (1981). The Biochemistry of silage. New York, EEUU: John Wiley \& Sons.

Morales, J., Acuña, V., \& Cruz, A. (2003). Industrialización del heno de calidad en sistemas bajo riego en Costa Rica. Costa Rica: Ministerio de Agricultura y Gandería (MAG), Instituto Nacional de Innovación y transferencia en Tecnología Agropecuaria (INTA), Fundecooperación para el Desarrollo Sostenible, Sistema Unificado de Información Institucional de Información Agropecuaria (SUNII) y Corporación ganadera (CORFOGA).

NRC (National Research Council). (2001). Nutrient Requirements of Dairy Cattle. 7th rev. ed. Washington, D.C., EEUU: National Academy Press.

Plasencia, J., \& Kvet, J. (1993). Production dynamic of Typha domingensis (Pers.) Kunth population in Cuba. Journal Aquatic Plant Management, 31, 240-243.

Rojas, A., Gómez, M., \& Aguirre, D. (1995). Caracterización nutricional y digestibilidad in vitro del ensilaje de mezclas de fruto de pejibaye (Bactris gasipaes) y morera (Morus alba). Agronomía Costarricense, 19(2), 39-43. 
SAS (2003). SAS 9.1.3. for Windows. Service Pack 4. Win_Pro plataforma. Copyright ${ }^{\circledast}$ 2002-2003 Cary NC.

Tobia, C. (2004). Introducción del ensilaje de soya en un sistema de producción Intensiva de leche en el trópico húmedo de Costa Rica. Tesis de doctorado. Universidad de Costa Rica, Costa Rica.

Tobia, C., \& Vargas, E. (2000). Inóculos bacterianos: una alternativa para mejorar el proceso fermentativo en los ensilajes tropicales. Nutrición Animal Tropical, 6(1),129-143.

Van Soest, P., \& Robertson, J. (1985). Analysis of forages and fibrous feeds. Ithaca, New York: Cornell University.

Weiss, W. (2004). Fine-tuning energy calculations. Proceedings Tri-State Dairy Nutrition Conference. Purdue University,
Michigan State University, Ohio State University, United States.

Villalobos-Villalobos, L., Arce-Cordero, J., \& WingChing-Jones, R. (2015). Costos de producción de ensilados de pastos tropicales elaborador en lecherías de Costa Rica. Nutrición Animal Tropical, 9(2), 27-48. doi: 10.15517/nat. v9i2.21462

WingChing-Jones, R., \& Alvarado, G. (2009). Valor nutricional del heno de transvala inoculado con el hongo Pleurotus ostreatus sp. Agronomía Costarricense, 33(1), 147-153.

WingChing-Jones, R., \& Leal-Rivera, J. (2014). Valoración agronómica y nutricional de la Typha domingensis, como alternativa de alimentación en animales ruminates. Nutrición Animal Tropical, 8(2), 24-35. 